\title{
Determination of histamine in human plasma: the European external quality control study 1988
}

\author{
E. OOSTING, E. NEUGEBAUER*, J. J. KEYZER† and W. LORENZ\$
}

BCO Centre for Research, Breda, *Biochemical and Experimental Division, Ind Department of Surgery, University of Cologne, $\ddagger$ Institute of Theoretical Surgery, Centre of Operative Medicine I, Philipps University, Marburg, FRG, and † Stichting Diagnostisch Centrum Eindhoven, Eindhoven, The Netherlands

\begin{abstract}
Summary
There is an increasing interest in measuring human plasma histamine levels in various clinical conditions. A variety of 'old' and newly developed techniques are applied to meet this demand. However, the discrepancy between reported reference values for histamine in human plasma measured using this variety of techniques, suggests the existence of a certain degree of inaccuracy and imprecision. We therefore organized an external quality control study on the reliability of current histamine determinations in European laboratories. Three lyophilized plasma quality control samples, in duplicate, covering the normal and pathological range of histamine concentrations $(0-45 \mathrm{nmol} / \mathrm{l})$, two different aqueous histamine standard samples and one solvent sample were sent to 10 laboratories for the analysis of their histamine content. The following methods were used: gas chromatography-mass spectrometry $(n=2)$, enzymatic single isotopic assay $(n=1)$, fluorometric-fluoroenzymatic assay $(n=3)$, radioimmunoassay $(n=3)$ and high performance liquid chromatography $(n=2)$. The study was performed and evaluated according to the approved recommendations (1983) of the International Federation of Clinical Chemistry (IFCC). The target values \pm s.d. of the three plasma samples were: $39.5 \pm 4.6 \mathrm{nmol} / 1(\mathrm{CV}=11 \cdot 6 \%), 2 \cdot 3 \pm 2.2 \mathrm{nmol} / 1(\mathrm{CV}=96 \%)$ and $8.9 \pm 1.5 \mathrm{nmol} / \mathrm{l}$ $(\mathrm{CV}=17 \%)$, respectively. The target values \pm s.d. of the two aqueous samples were: $0 \cdot 9 \pm 1 \cdot 1 \mathrm{nmol} / 1(\mathrm{CV}=120 \%$; true value: $0.00 \mathrm{nmol} / \mathrm{l})$ and $10 \cdot 2 \pm 0 \cdot 5 \mathrm{nmol} / 1(\mathrm{CV}=5 \cdot 3 \%$; true value: $10 \cdot 0 \mathrm{nmol} / \mathrm{l}$ ), respectively. A Youden plot of two unrelated plasma samples in the pathological range defined 7/11 results as accurate and precise. The Youden plot of the two unrelated aqueous samples only defined $6 / 11$ results as accurate and precise. In general, estimating histamine concentrations within the normal range seemed to be the most difficult part of measuring histamine in human plasma samples. It is suggested to define reference standards, methods and laboratories for plasma histamine determinations.
\end{abstract}

Clinical and Experimental Allergy, Vol. 20, pp. 349-357. Submitted 3 January 1990; revised 7 February 1990; accepted 7 February 1990.

\section{Introduction}

Several assays have been developed, varying from bioassay, fluorometry, enzymatic assay, chromatography to radioimmunoassay [1-43] (Table 1), for studying endogenous histamine release in man. The determination of

Correspondence: Dr E. Neugebauer, Biochemical and Experimental Division, IInd Department of Surgery, University of Cologne, Ostmerheimer Strasse 200, 5000 Cologne 91, FRG. histamine concentrations in plasma has important applications [14,20,21,27,30,43-54]; because of the short halflife time of histamine (c. $2 \mathrm{~min}$.) $[55,56]$ this is especially important in the field of controlled studies, in which it is possible to collect blood samples at regular times. However, in a meta-analysis evaluation about the role of histamine as a mediator in septic/endotoxic shock, threequarters of the relevant studies are quoted as being an unreliable assay for measuring histamine in human 
Table 1. A review of reported reference values of histamine in human plasma (nmol/1). Literature from 1970 to 1989 was screened by means of computer search, using the keywords: 'histamine', 'analysis' and 'plasma'

\begin{tabular}{|c|c|c|c|c|}
\hline Technique and reference & Reference no. & $n^{*}$ & $\begin{array}{c}\text { Mean } \pm \text { s.d. } \\
(\dagger \pm \text { s.e.m. })\end{array}$ & Range \\
\hline \multicolumn{5}{|l|}{ Bioassay } \\
\hline Barsoum and Smirk, 1936 & [1] & 21 & $54 \cdot 1$ & $27 \cdot 0-108 \cdot 1$ \\
\hline Anrep et al., 1944 & [2] & 7 & $54 \cdot 1$ & $18 \cdot 0-99 \cdot 1$ \\
\hline Adam et al., 1957 & [3] & 5 & $<9 \cdot 0$ & $<9 \cdot 0-10 \cdot 8$ \\
\hline \multicolumn{5}{|l|}{ Fluorometry } \\
\hline Noah and Brand, 1961 & [4] & 12 & $27 \cdot 0$ & $9 \cdot 0-81 \cdot 1$ \\
\hline Beall, 1963 & [5] & 15 & $54 \cdot 1$ & $27 \cdot 0-90 \cdot 1$ \\
\hline Thompson and Walton, 1964 & [6] & 16 & $72 \cdot 1$ & \\
\hline Garden, 1966 & [7] & 47 & $45 \cdot 0$ & $36 \cdot 0-54 \cdot 1$ \\
\hline Graham et al., 1968 & [8] & 62 & $5 \cdot 6 \pm 2 \cdot 7$ & $0 \cdot 9-12 \cdot 6$ \\
\hline Lorenz et al., 1972 & [9] & 54 & $6 \cdot 2 \pm 2 \cdot 3$ & $0 \cdot 9-12 \cdot 6$ \\
\hline Lorenz and Doenicke, 1978 & [10] & 40 & $2 \cdot 7$ & $0 \cdot 0-8 \cdot 1$ \\
\hline Schöning et al., 1982 & [11] & 299 & $3 \cdot 2$ & $0 \cdot 0-8 \cdot 2$ \\
\hline Rehn et al., 1987 & [12] & 12 & $1 \cdot 1 \pm 0 \cdot 7$ & $0.5-1.9$ \\
\hline \multicolumn{5}{|l|}{ Enzymatic single isotopic assay } \\
\hline Bruce et al., 1976 & [13] & 29 & $4 \cdot 0 \pm 3 \cdot 4$ & $0 \cdot 0-10 \cdot 8$ \\
\hline Stevenson et al., 1976 & [14] & 10 & $<2 \cdot 3$ & \\
\hline Subramanian et al., 1978 & [15] & 50 & $2 \cdot 0$ & \\
\hline Shaff and Beaven, 1979 & [16] & 19 & $5.4 \pm 0.9 \dagger$ & $1 \cdot 8-12 \cdot 6$ \\
\hline Bruce et al., 1979 & [17] & 25 & $5 \cdot 4 \pm 0.9$ & \\
\hline Almeida et al., 1980 & [18] & 8 & $5 \cdot 4 \pm 0 \cdot 9$ & \\
\hline Brown et al., 1980 & [19] & 17 & $3.4 \pm 0.7$ & $0 \cdot 8-4 \cdot 7$ \\
\hline Moss et al., 1981 & [20] & 6 & $9 \cdot 7 \pm 6 \cdot 0$ & \\
\hline Barnes and Brown, 1981 & [21] & 6 & $3 \cdot 4 \pm 0 \cdot 6$ & \\
\hline Guilloux et al., 1981 & [22] & 50 & $6 \cdot 9 \pm 5 \cdot 5$ & \\
\hline Dyer et al., 1982 & [23] & 51 & $2 \cdot 9 \pm 1 \cdot 5$ & $0 \cdot 0-7 \cdot 8$ \\
\hline Verburg et al., 1983 & [24] & 8 & $2.7 \pm 0.7$ & $1 \cdot 9-4 \cdot 3$ \\
\hline Haimart et al., 1985 & [25] & 18 & $3.9 \pm 1.7$ & \\
\hline Rauls et al., 1986 & [26] & 3 & $1.9 \pm 0 \cdot 2$ & $1.7-2.1$ \\
\hline Asad et al., 1987 & [27] & 30 & $1.9 \pm 0.2 \dagger$ & $0 \cdot 9-4.5$ \\
\hline Harvima et al., 1988 & [28] & 35 & $6 \cdot 5 \pm 4 \cdot 3$ & $0 \cdot 2-21 \cdot 0$ \\
\hline \multicolumn{5}{|l|}{ Enzymatic double isotopic assay } \\
\hline Miller et al., 1970 & [29] & 11 & $5 \cdot 4 \pm 1 \cdot 8$ & $3 \cdot 6-9 \cdot 0$ \\
\hline Barnes et al., 1982 & [30] & 26 & $2 \cdot 4 \pm 0 \cdot 2 \dagger$ & \\
\hline Ind et al., 1983 & [31] & 31 & $1.9 \pm 0.2 \dagger$ & \\
\hline \multicolumn{5}{|c|}{ High performance liquid chromatography } \\
\hline Tsuruta et al., 1978 & [32] & 10 & $5 \cdot 5 \pm 1 \cdot 4$ & \\
\hline Yamatodani et al., 1985 & [33] & 20 & $4 \cdot 0 \pm 1 \cdot 6$ & \\
\hline Harsing et al., 1986 & [34] & 88 & $7 \cdot 2 \pm 2 \cdot 6$ & $1 \cdot 3-15 \cdot 9$ \\
\hline Arakawa and Tachibana, 1986 & [35] & 5 & $8 \cdot 1 \pm 4 \cdot 5$ & \\
\hline Scheinman et al., 1988 & [36] & 6 & 0.0 & \\
\hline Czerwonka et al., 1988 & [37] & 10 & $2 \cdot 4 \pm 2 \cdot 3$ & $0.0-3.6$ \\
\hline Asskali and Förster, 1989 & [38] & & $3 \cdot 4 \pm 1 \cdot 1$ & \\
\hline \multicolumn{5}{|c|}{ Gas chromatography-mass spectrometry } \\
\hline Mita et al., 1980 & [39] & 5 & $7 \cdot 5 \pm 3 \cdot 3$ & $4 \cdot 1-12 \cdot 9$ \\
\hline Keyzer et al., 1984 & [40] & 25 & $2 \cdot 1 \pm 0 \cdot 8$ & $0 \cdot 8-3.6$ \\
\hline Payne et al., 1989 & [41] & 3 & $0 \cdot 9 \pm 0 \cdot 2$ & $0 \cdot 8-1 \cdot 2$ \\
\hline \multicolumn{5}{|l|}{ Radioimmunassay } \\
\hline McBride et al., 1988 & [42] & 40 & $1.7 \pm 0.7$ & $0 \cdot 8-5 \cdot 0$ \\
\hline
\end{tabular}

* $n=$ number of subjects. The overall mean \pm s.d. of the means that were published in the periods $1960-1969,1970-1979$ and $1980-1989$ were $40 \cdot 8 \pm 25 \cdot 5 \quad(n=5$; $\mathrm{CV}=63 \%), 4 \cdot 6 \pm 1 \cdot 5(n=8 ; \mathrm{CV}=33 \%)$ and $3.8 \pm 2 \cdot 5 \mathrm{nmol} / \mathrm{l}(n=25 ; \mathrm{CV}=67 \%)$, respectively. See also $[47,56]$. 
plasma and the authors conclude it is irrational to develop theories about any pathomechanism of histamine release before this error has been carefully excluded' [51]. Also the discrepancy between recently reported reference values for histamine in human plasma (Table 1: 19801989; $n=25 ; \mathrm{CV}=67 \%$ ) suggests that besides possible sample collection problems [40] and biorhythmic differences [12], inaccuracy and imprecision may exist, leading to unreliable reports. This thought has been confirmed in 1980 by Gleich and Hull [57], who published a study in which 22 laboratories participated, and four different techniques for the measurement of histamine in plasma and buffered aqueous solutions containing known amounts of histamine were evaluated: enzymatic double isotopic assay, enzymatic single isotopic assay, automated fluorometric and manual fluorometric assay.

There were several methodological pitfalls in the study of Gleich and Hull [57]. The variation in reported reference values, the increasing interest in measuring histamine, the improvements of 'old' techniques and the development of new chromatographic and immunological methods inspired us to organize a renewed external quality control study on histamine measurement in plasma in European laboratories, covering five different techniques: gas chromatography-mass spectrometry (GCMS), enzymatic double isotopic assay (EDIA), fluorometric-fluoroenzymatic assay (FFEA), radioimmunoassay (RIA) and high performance liquid chromatography (HPLC). For each technique two laboratories were selected.

This study was performed and evaluated according to the approved recommendations of the International Federation of Clinical Chemistry (IFCC), dealing on external quality-control studies in clinical chemistry [58].

Our aims were to establish the ability of several laboratories using different techniques to obtain the same results in the same specimens, to provide an overall measure of inaccuracy and imprecision and to act as an educational stimulus to improve the performances by informing the laboratories about their results and to compare them with those of the other participating laboratories.

The results of this study were partly presented at the Munich Consensus Development Conference on Histamine Determination, December 3-7, 1988 [59,60] and at the 18th Meeting of the European Histamine Research Society, May 17-20, 1989, The Netherlands [61].

\section{Materials and methods}

\section{Materials}

Reagents. Histamine dihydrochloride (extra pure) was purchased from Merck, Darmstadt, FRG; water (Baker
Table 2. The participating laboratories with the reported reference(s) of their method

\begin{tabular}{rlr} 
Result & Technique & Reference \\
\hline 1 & Gas chromatography-mass spectrometry & {$[40,48]$} \\
2 & Gas chromatography-mass spectrometry & {$[40]$} \\
3 & Enzymatic single isotopic assay & {$[15]$} \\
4 & Fluorometric-fluoroenzymatic assay & {$[9]$} \\
5 & Fluorometric-fluoroenzymatic assay & {$[9]$} \\
6 & Fluorometric-fluoroenzymatic assay & {$[9]$} \\
7 & Radioimmunoassay & {$[63]$} \\
8 & Radioimmunoassay & {$[63]$} \\
9 & Radioimmunoassay & {$[63]$} \\
10 & High performance liquid chromatography & {$[64]$} \\
11 & High performance liquid chromatography & {$[38]$} \\
\hline
\end{tabular}

analysed HPLC ${ }^{\circledR}$ reagent) from JT Baker, Deventer, The Netherlands; and hydrochloric acid 30\% (Suprapur $^{\circledR}$ ) from Merck, Darmstadt, FRG.

Histamine stock solution. Histamine dihydrochloride was dried at $80^{\circ} \mathrm{C}$ for one night and cooled at room temperature in a desiccator for $5 \mathrm{hr}$. A portion was dried to a constant weight of $57.49 \mathrm{mg}$ in a desiccator and dissolved in $250 \mathrm{ml}$ of $0.1 \mathrm{~mol} / 1$ hydrochloric acid. Exactly $1 \mathrm{ml}$ of this solution was diluted further with $0.1 \mathrm{~mol} / 1$ hydrochloric acid to $250 \mathrm{ml}$, resulting in a histamine stock solution containing $4.996 \mu \mathrm{mol} / \mathrm{l}$ histamine. This histamine stock solution was used to prepare aqueous and plasma histamine quality control samples.

Stability control. During the preparatory phase (see Methods) the effect of lyophilizing plasma samples and subsequent storage for 4 weeks at $+4^{\circ} \mathrm{C}$ on their histamine concentration was studied by comparison with the histamine concentration obtained in the same plasma samples without lyophilization and storage for only a few days at $-20^{\circ} \mathrm{C}$. Twelve $5 \mathrm{ml}$ portions of plasma containing three different amounts of histamine, between 0 and $60 \mathrm{nmol} / \mathrm{l}$, were prepared by adding different amounts of a histamine stock solution to pooled human plasma (four portions of each concentration: Ia-d, IIa-d, III a-d). Six portions (two of each concentration: Ia, b, IIa, b and IIIa, b) were dispensed into $17-\mathrm{ml}$ glass ampules and lyophilized overnight and sealed with butyl-rubber torches. After 4 weeks storage at $+4^{\circ} \mathrm{C}$, the content of the ampules was redissolved with water and the histamine concentration determined. The six remaining portions (two of each concentration: Ic, d, IIc, d and IIIc, d) were dispensed into polypropylene tubes, stored at $-20^{\circ} \mathrm{C}$ and analysed within the same week of preparation. All samples were analysed by GCMS $[40,48]$. 

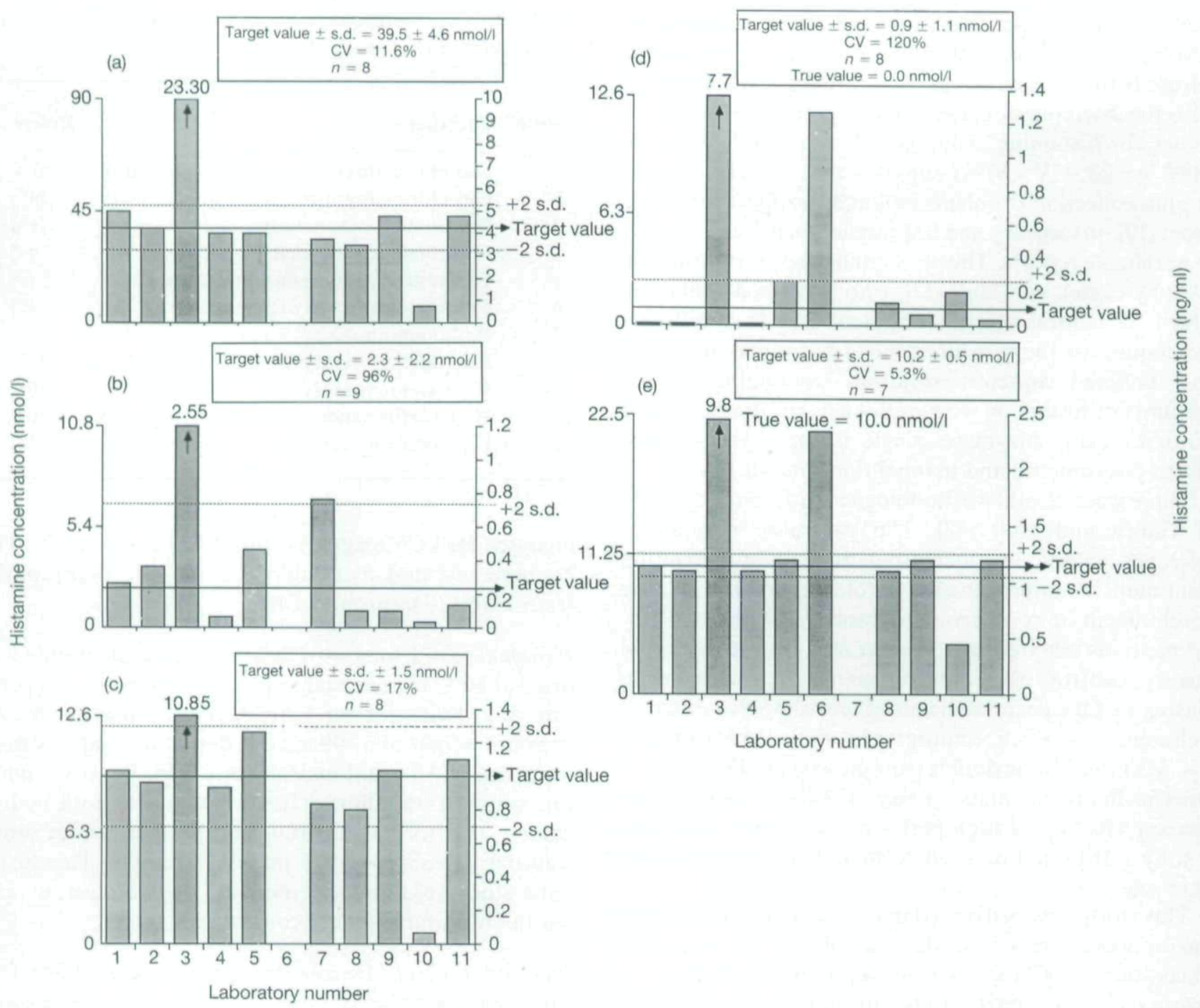

Fig. 1. Individual results on quality control plasma samples I (a), II (b) and III (c) and quality control aqueous samples IV (d) and $\mathrm{V}(\mathrm{e})$.

Plasma histamine preparation. Blood was collected from 13 volunteers, using no medication at all (one female and 12 males, age 22-57 yr), by venepuncture in dry EDTAcontaining evacuated blood collection tubes of $10 \mathrm{ml}$ (Venoject ${ }^{\circledR}$, Terumo, Belgium). From the nine blood samples/volunteer the first one was always discarded. The samples were immediately cooled in melting ice $\left(0-4^{\circ} \mathrm{C}\right)$ and plasma was prepared within $30 \mathrm{~min}$ after blood collection by centrifugation in a cooled centrifuge $\left(+4^{\circ} \mathrm{C}\right)$ at $1000 \times g$ for $10 \mathrm{~min}$. Using polypropylene pipettes the plasma was transferred to polypropylene tubes and centrifuged again for $10 \mathrm{~min}$ at $3000 \times \mathrm{g}$ in a cooled centrifuge $\left(+4^{\circ} \mathrm{C}\right)$. The supernatants were pooled in a polypropylene container to give a final volume of approximate $360 \mathrm{ml}$. After gentle mixing this plasma pool was subdivided in three equal pools (I-III) in polypropylene containers and cooled.

Plasma histamine quality control samples. Three different quality control samples were prepared. Quality control sample I was prepared by adding $1 \mathrm{ml}(4.996 \mathrm{nmol}$ histamine) and quality control sample III by adding 200 $\mu \mathrm{l}(0.999 \mathrm{nmol}$ histamine $)$ of the histamine stock solution to plasma pool I and III, respectively. Quality control sample II consisted of plasma portion II without added histamine. Exactly 5 -g portions $(4 \cdot 9979 \pm 0 \cdot 0050$; mean \pm s.d.) of the quality control samples I, II and III were dispensed into $17 \mathrm{ml}$ glass ampules and coded. The 


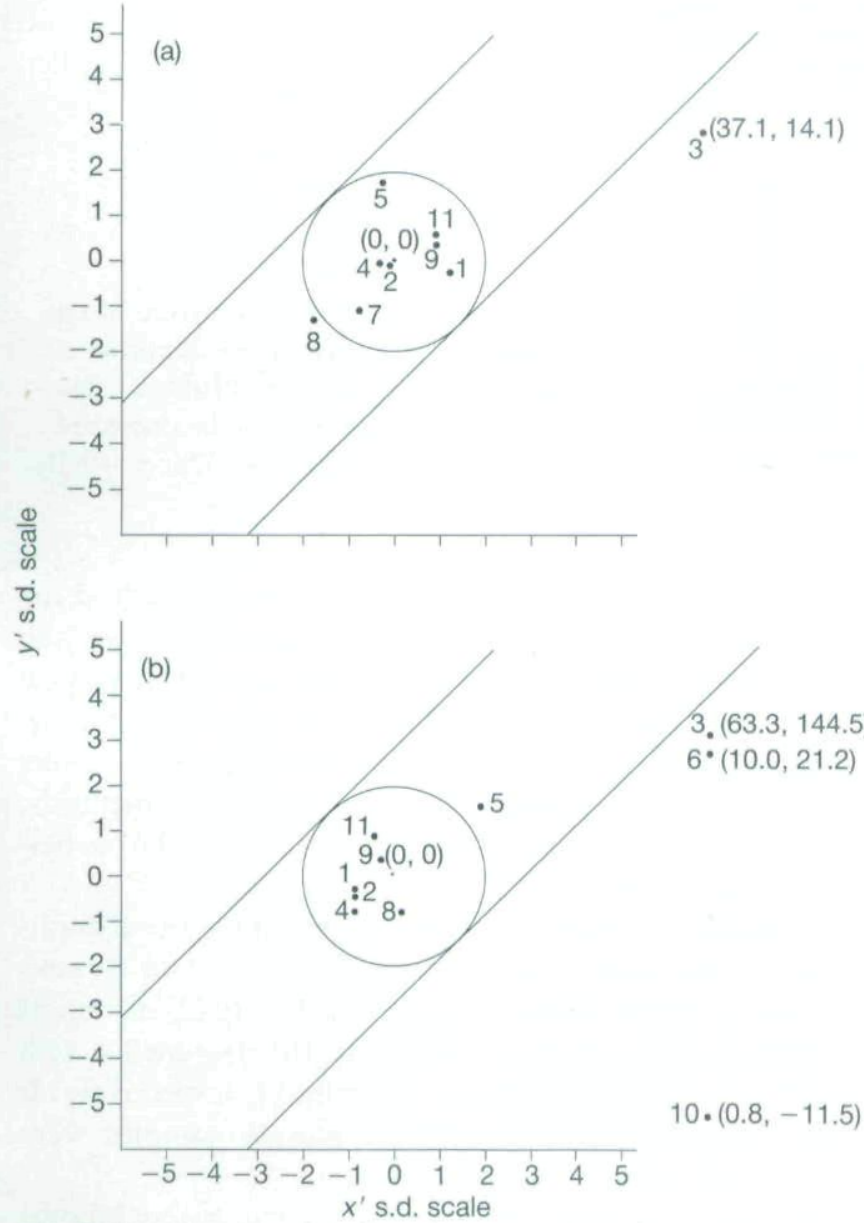

Fig. 2. Youden plots, (a) of quality control plasma samples I $\left(x^{\prime}\right)$ and III $\left(y^{\prime}\right)$ and (b) of quality control aqueous samples IV $\left(x^{\prime}\right)$ and $\mathrm{V}\left(y^{\prime}\right)$.

plasma samples were lyophilized overnight and sealed with a butyl-rubber torch. At the time of analysis the participants were asked to redissolve the contents into $5 \mathrm{ml}$ distilled water (HPLC quality, Baker), to mix for $5 \mathrm{~min}$ and to analyse the resulting solutions for the histamine concentration.

Aqueous histamine quality control samples. Two different quality control samples were prepared. The first one (sample IV) consisted only of $0.1 \mathrm{~mol} / 1$ hydrochloric acid with no exogenous histamine. Sample V was prepared by diluting $200 \mu \mathrm{l}$ of the histamine stock solution with $0 \cdot 1$ $\mathrm{mol} / \mathrm{l}$ hydrochloric acid to $100 \mathrm{ml}$ to give a final concentration of $10 \mathrm{nmol} / 1$ histamine. Exactly $5 \mathrm{ml}$ of both quality control samples were dispensed into $17-\mathrm{ml}$ glass ampules and sealed with butyl-rubber torches.

\section{Methods}

Design of the study. A 3-month preparatory phase (JuneAugust 1988) was needed to design and start the study.
Table 3. A summary of statements about accuracy and precision of the participating laboratories as a result of presentation in Youden plots of histamine determinations in plasma and aqueous solutions

\begin{tabular}{|c|c|c|c|c|}
\hline & \multicolumn{2}{|c|}{ Accuracy } & \multicolumn{2}{|c|}{ Precision } \\
\hline & Plasma & Aqueous & Plasma & Aqueous \\
\hline \multicolumn{5}{|c|}{ Gas chromatography-mass spectrometry } \\
\hline 1 & + & + & + & + \\
\hline 2 & + & + & + & + \\
\hline \multicolumn{5}{|c|}{ Enzymatic single isotopic assay } \\
\hline 3 & - & - & - & - \\
\hline \multicolumn{5}{|c|}{ Fluorometric-fluoroenzymatic assay } \\
\hline 4 & + & + & + & + \\
\hline 5 & + & - & + & + \\
\hline 6 & * & - & $*$ & - \\
\hline \multicolumn{5}{|c|}{ Radioimmunoassay } \\
\hline 7 & + & $*$ & + & $*$ \\
\hline 8 & - & + & + & + \\
\hline 9 & + & + & + & + \\
\hline \multicolumn{5}{|c|}{ High performance liquid chromatography } \\
\hline 10 & - & - & + & - \\
\hline 11 & + & + & + & + \\
\hline
\end{tabular}

The laboratories are indicated by numbers corresponding with Figs 1 and 2 and Table 2.

* Laboratories unable to produce results.

This included (1) the preparation of the samples and their control for stability under field conditions (see Materials), (2) the preparation of standardized and clear-cut instructions and report forms, including a questionnaire about the method used and (3) the selection of experienced participants and current methods with agreement to perform the analysis within 6 weeks.

Each participating laboratory was provided by mail with (1) plasma samples I-III in duplicate, (2) aqueous samples IV and V, (3) one solvent sample ( $15 \mathrm{ml} 0 \cdot 1 \mathrm{~mol} / 1$ hydrochloric acid, Suprapur ${ }^{\circledR} 30 \%$ in water; HPLC quality, Baker) and (4) instructions and report forms. No participant had information on the amount of histamine in the samples. The samples were only identified as plasma or aqueous samples.

In total, 10 European laboratories were asked to participate in this study, two for each analytical method: GCMS, EDIA, FFEA, RIA or HPLC.

Evaluation of the results. The results were evaluated according to the recommendation on quality control in clinical chemistry given by the IFCC [58]. Target values 


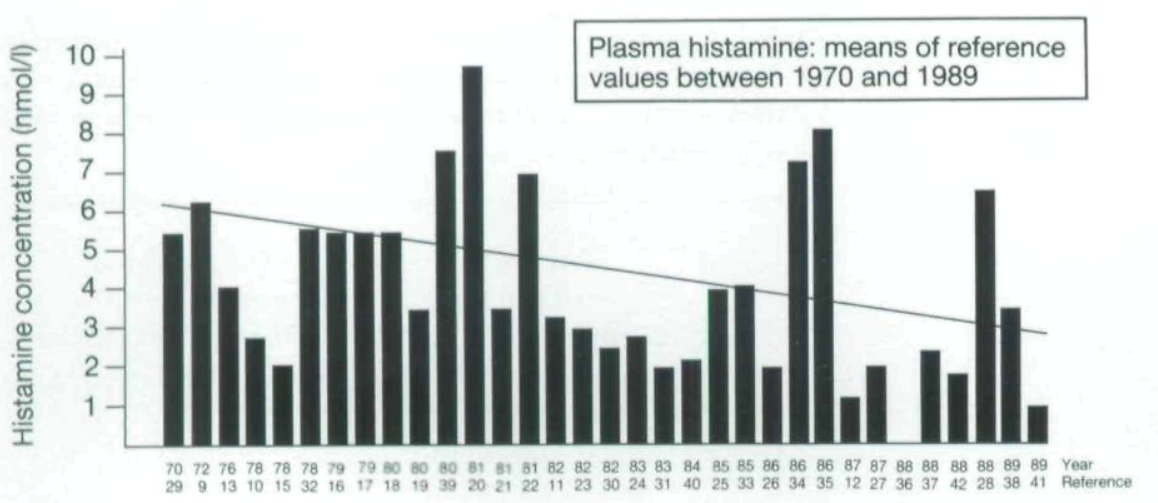

Fig. 3. A graphical presentation of the means of reference values, reported between 1970 and 1989 (Table 1). The linear regression line can be described by: $y=18 \cdot 52-0 \cdot 18 x(n=33 ; r=-0 \cdot 36)$. were defined as the grand mean of all results after removal of 'outliers'. 'Outliers' are discordant data, not representative of the majority of results and were defined as results lying outside the mean \pm 3 s.d. The imprecision and inaccuracy of the different methods and laboratories was calculated using Youden plots [62]. The Youden plot uses a graphical display of two unrelated specimens of different analyte concentration and illustrates, in a limited fashion, the presence of imprecision and inaccuracy. Results on specimens $\mathrm{X}$ and $\mathrm{Y}$ from each laboratory are transformed by the relationship $x_{\mathrm{i}}^{\prime}=\left(x_{\mathrm{i}}-\bar{x}\right) / \mathrm{s}$.d. $x$ and $y_{\mathrm{i}}^{\prime}=\left(y_{\mathrm{i}}-\bar{y}\right) / \mathrm{s} . \mathrm{d} . y$, where $\bar{x}$ and $\bar{y}$ are the means of all $x$ and $y$, respectively, and s.d. $x$ and s.d. $y$ are the standard deviations of all $x$ and $y$, respectively (outliers excluded in each case). Transformed pairs of values can then be plotted. The s.d. scales on both $x$ and $y$ axes are identical, so that a circle may be drawn with centre 0,0 (transformed from $x, y$ ) and radius 2 s.d., which, in theory, should contain approximately $95 \%$ of the results. Two parallel tangents, at $45^{\circ}$ to both $x$ and $y$ axes, are drawn. Results outside the circle show the presence of inaccuracy. Results outside the parallel lines indicate that there is a major component of imprecision.

According to IUPAC rules, the plasma histamine concentration is expressed in $\mathrm{nmol} / \mathrm{l}$, although we are aware of the fact that in many reports the old unit, $\mathrm{ng} / \mathrm{ml}$, still is used. The advantage of $\mathrm{nmol} / \mathrm{l}$ is that the base can not be mistaken with the salt. The conversion from nmol/l into $\mathrm{ng} / \mathrm{ml}$ is multiplication by $0 \cdot 111$.

All participating laboratories were informed about the results before using them for any kind of presentation. The results of each individual participant was and will remain strictly confidential.

\section{Results}

The difficulties that arise in a multicentre study like this, may be illustrated by the following facts. Only two participants reported their results within the specified time. The participants asked to analyse their samples with the EDIA technique were unable to run the method for different reasons; one of them used the FFEA and the other one the enzymatic single isotopic assay (ESIA). One laboratory used two methods, HPLC and RIA, for the same set of samples. For this reason we received 11 results all together. In Table 2 the 11 analytical methods, combined with the reference(s) as reported by the participants, are shown.

The mean histamine concentrations in the three duplicate plasma samples after (1) lyophilization and 4 weeks of storage at $+4^{\circ} \mathrm{C}(\mathrm{Ia}, \mathrm{b}$; IIa, b; IIIa, b) and (2) storage at $-20^{\circ} \mathrm{C}$ for a few days (Ic, d; IIc, d; IIIc, d) were $3 \cdot 4,13 \cdot 8$ and $53 \cdot 4$, and $3 \cdot 3,13.8$ and $54.7 \mathrm{nmol} / \mathrm{l}$, respectively. It was concluded that lyophilized plasma samples were stable enough to be used in this study.

Figure 1 shows the results of the participating laboratories after analysis of the five different samples. One participant was unable to measure histamine in the plasma samples reliably (no. 6: FFEA) and another one had problems with the determination in the aqueous samples (no. 7: RIA).

The imprecision and inaccuracy of the different methods for the measurement of histamine in plasma and aqueous solutions are shown in Fig. 2. Figure 2a is a Youden plot of the two unrelated plasma samples I and III. These plasma samples have histamine concentrations that might be defined as pathological $(>9 \mathrm{nmol} / \mathrm{l})$ [65]. Concerning the measurement of histamine in plasma, laboratories 3 (ESIA), 8 (RIA) and 10 (HPLC) were inaccurate (outside the circle) and laboratory 3 (ESIA) was also imprecise (outside the parallel lines). Figure $2 \mathrm{~b}$ is a Youden plot of the two unrelated aqueous histamine solutions. Concerning the measurement of histamine in these samples, laboratories 3 (ESIA), 5 (FFEA), 6 (FFEA) and 10 (HPLC) were inaccurate (outside the circle) and laboratories 3 (ESIA), 6 (FFEA) and 10 (HPLC) were also imprecise (outside the parallel lines). The results of the Youden plots are summarized in Table 3. 


\section{Discussion}

In this quality-control study we have attempted to compare five comonly used histamine assays in different laboratories in Europe for the determination of clinically relevant concentrations of histamine in human plasma $(0-45 \mathrm{nmol} / \mathrm{l})$ and aqueous solutions $(0-10 \mathrm{nmol} / \mathrm{l})$. For this purpose, lyophilized plasma samples were checked with regard to stability and found to be suitable for use in the present quality control study.

Unfortunately, we were unable to incorporate two EDIAs in this study. Eventually, the two laboratories concerned reported results obtained with other methods, i.e. FFEA and ESIA. Nevertheless, the EDIA method is commonly used and claims good results [29-31] (Table 1).

In contrast to Gleich and Hull [57], who found great variation of results obtained by different laboratories, this study showed that $7 / 11$ results obtained with the five different methods were accurate, and precise in the plasma range of histamine between 9 and $45 \mathrm{nmol} / 1$ (Figs la and 1c, 2a; Table 3). The results on plasma II (Fig. 1b: normal plasma pool without addition of external histamine) confirm this observation, although in a Youden plot making use of the results on plasma II from laboratory 8 would just have been accurate, while laboratory 7 would just have been inaccurate. Remarkable in plasma II is the coefficient of variation of $96 \%$, which is much higher than in the other two plasma samples (III: $17 \%$ and I: $11 \cdot 6 \%$ ). However, this high value is in accord with the variation in recently reported reference values between 1980 and 1989 (Table 1: $\mathrm{CV}=67 \%$ ).

Surprisingly, with respect to measuring histamine in a simple matrix such as aqueous solutions IV and V, less laboratories were precise and accurate (6/11) in comparison with the determination in plasma (7/11) (Figs 1d and $1 \mathrm{e}, 2 \mathrm{~b}$; Table 3 ). This may be due to the lower concentration of histamine in these samples. In correspondence with the results on the plasma samples, the lowest concentrations also showed the greatest variation: $\mathrm{CV}=120 \%$. Only $3 / 11$ laboratories really reported 0 $\mathrm{nmol} / \mathrm{l}$ in the blank sample IV (Fig. 1d).

In general, estimating concentrations within the normal range seems to be the most difficult part of measuring histamine in human plasma. As in many studies these basal values are the starting point for further investigations and conclusions, this subject requires special attention.

The histamine concentration eventually measured in plasma, while using a certain analytical method, is the result of (1) the 'true' value of circulating plasma histamine in the patient, (2) sample collection and plasma preparation and (3) the analytical method.
(1) Unwanted influence may be caused by the ingestion of histamine-rich food [66].

(2) During sample collection by venepuncture and plasma preparation, histamine may be released from basophilic leucocytes (mainly) and mast cells. This may be caused by: injury, venous stasis, haemolysis, clotting, centrifuging too fast and storage of the blood samples, after collection, for more than $30 \mathrm{~min}$ and not on ice $[40,51,67]$. In the past clinical studies have been published in which serum histamine was measured [68,69], although, because of complement activation during blood clotting, a histamine value in serum will inform about the number of releasability of basophils rather than about the actual concentration of 'free' histamine in blood [40].

(3) Quality-control studies like this can help to solve this problem by evaluating the individual method.

The most recent GCMS and RIA studies suggest a mean reference value for plasma histamine of approximately $1-3 \mathrm{nmol} / 1[40-42]$, which is confirmed by the linear regression line in the graphical presentation of the reported reference values from 1970 to 1989 , as listed in Table 1 (Fig. 3). As can be seen from Table 1 and Fig. 3, over the last 20-30 years the reference values have been decreased thanks to more sophisticated methods, and are increasingly able to prevent false interference. Also the problems of sample taking, provoking falsely high results, are better recognized.

Observing the individual accuracy within the five different techniques (Table 3), it is conceivable that the negative scores of some laboratories using FFEA, RIA or HPLC were not due to unreliable methods, but due to problems with the performances at the time of the study. Indications for this are the accurate performances of other laboratories with the same technique and using more or less the same method.

This study revealed the need for further and more extended quality-control studies. Defined reference standards, methods and laboratories for plasma histamine measurements are now required. This seems particularly important because various methods, also applicable to less specialized laboratories, are now on the market or will shortly appear.

\section{References}

1 Barsoum GS, Smirk FH. Observations on the histamine yielding substance in the plasma and red cells of normal subjects and patients with congestive heart failure. Clin Sci 1936; 2:337-55.

2 Anrep GV, Barsoum GS, Salama S, Souidan Z. Liberation of histamine during reactive hyperaemia and muscle contraction in man. J Physiol (Lond) 1944; 103:297-305.

3 Adam HM, Hardwick DC, Spencer KEV. A method of 
estimating histamine in plasma. Br J Pharmacol 1957; 12:397-405.

4 Noah JW, Brand A. A fluorometric method to determine the levels of histamine in human plasma. J Allergy 1961; 32:23642.

5 Beall GN. Plasma histamine concentrations in allergic diseases. J Allergy 1963; 34:8-15.

6 Thompson WL, Walton RP. Evaluation of plasma histamine levels in the dog following administration of muscle relaxants, opiates and macromolecular polymers. J Pharmacol Exp Ther 1964; 143:131-6.

7 Garden JW. Plasma and sweat histamine concentrations after heat exposure and physical exercise. J Appl Physiol 1966; 21:631-5.

8 Graham H, Scarpellini JAD, Hubka BP, Lowry OH. Measurement and normal range of free histamine in human blood plasma. Biochem Pharmacol 1968; 17:2271-80.

9 Lorenz W, Reimann H-J, Barth H, et al. A sensitive and specific method for the determination of histamine in human whole blood and plasma. Hoppe-Seyler Z Physiol Chem 1972; 353:911-20.

10 Lorenz W, Doenicke A. Histamine release in clinical conditions. Mt Sinai J Med (NY) 1978; 45:357-86.

11 Schöning B, Lorenz W, Doenicke A. Prophylaxis of anaphylactoid reactions to a polypeptidal plasma substitute by $\mathrm{H}_{1-}$ plus $\mathrm{H}_{2}$-receptor antagonists: synopsis of three randomized controlled trials. Klin Wochenschr 1982; 60:1048-55.

12 Rehn D, Reimann HJ, von der Ohe M, Schmidt U, Schmel A, Hennings G. Biorhythmic changes of plasma histamine levels in healthy volunteers. Agents Actions 1987; 22:24-9.

13 Bruce C, Weatherstone R, Seaton A, Taylor WH. Histamine levels in plasma, blood and urine in severe asthma, and the effect of corticosteroid treatment. Thorax 1976; 31:724-9.

14 Stevenson DD, Arroyave CM, Bhat KN, Tan EM. Oral aspirin challenges in asthmatic patients: a study of plasma histamine. Clin Allergy 1976; 6:493-505

15 Subramanian N, Mitznegg P, Domschke W. A rapid and sensitive enzymatic isotopic method for routine assay of histamine in blood, plasma and biopsy tissue: re-evaluation, Acta-Hepato-Gastroenterol 1978; 25:456-8.

16 Shaff RE, Beaven MA. Increased sensitivity of the enzymatic isotopic assay of histamine: measurement of histamine in plasma and serum. Anal Biochem 1979; 94:425-30.

17 Bruce C, Taylor WH, Westwood A. An improved radioenzymatic assay for histamine in human plasma, whole blood, urine and gastric juice. Ann Clin Biochem 1979; 16:259-64.

18 Almeida AP, Flye W, Deveraux D, Horokova Z, Beaven MA. Distribution of histamine and histaminase (diamine oxidase) in blood of various species. Comp Biochem Physiol 1980; 67:187-90.

19 Brown MJ, Ind PW, Barnes PJ, Jenner DA, Dollery CT. A sensitive and specific radiometric method for the measurement of plasma histamine in normal individuals. Anal Biochem 1980; 109:142-6.

20 Moss J, Rosow CE, Savarese JJ, Philibin DM, Kniffen KJ. Role of histamine in the hypotensive action of d-tubocurarine in humans. Anesthesiology 1981; 55:19-25.

21 Barnes PJ, Brown MJ. Venous plasma histamine in exercise and hyperventilation-induced asthma in man. Clin Sci 1981; 61:159-62.
22 Guilloux L, Hartmann D, Ville G. Enzymatic isotopic assay for human plasma histamine. Clin Chim Acta 1981; 116:269-75.

23 Dyer J, Warren K, Merlin S, Metcalfe DD, Kaliner M. Measurement of plasma histamine: description of an improved method and normal values. J Allergy Clin Immunol 1982; 70:82-7.

24 Verburg KM, Bowsher RR, Henry DP. A new radioenzymatic assay for histamine using purified histamine N-methyltransferase. Life Sci 1983; 32:2855-67.

25 Haimart M, Launay JM, Zürcher G, Cauet N, Dreux C, Da Prada M. Simultaneous determination of histamine and $\mathrm{N}^{\tau}$-methylhistamine in biological samples by an improved enzymatic single isotopic assay. Agents Actions 1985; 16:71-5.

26 Rauls DO, Ting S, Lund M. Analysis of plasma histamine: a modification of the enzymatic isotopic assay. J Allergy Clin Immunol 1986; 77:673-6.

27 Asad SI, Murdoch R, Youlten LJF, Lessof MH. Plasma level of histamine in aspirin-sensitive urticaria. Ann Allergy 1987; 59:219-22.

28 Harvima RJ, Harvima IT, Fräki JE. Optimization of histamine radio enzyme assay with purified histamine-Nmethyltransferase. Clin Chim Acta 1988; 171:247-56.

29 Miller RL, McCord C, Sanda M, Bourne HR, Melmon KL. Application of the enzymatic double isotope dilution assay for the study of histamine in plasma. J Pharmacol Exp Ther $1970 ; 175: 228-34$.

30 Barnes PJ, Ind PW, Brown MJ. Plasma histamine and cathecholamines in stable asthmatic subjects. Clin Sci 1982; 62:661-5.

31 Ind PW, Barnes PJ, Brown MJ, Causon R, Dollery CT. Measurement of plasma histamine in asthma. Clin Allergy 1983; 13:61-7.

32 Tsurata Y, Kohashi K, Ohkura Y. Determination of histamine in plasma by high-speed liquid chromatography. J Chromatogr 1978; 146:490-3.

33 Yamatodani A, Fukuda $\mathrm{H}$, Wada H, Iwaeda T, Watanabe T. High-performance liquid chromatographic determination of plasma and brain histamine without previous purification of biological samples: cation-exchange chromatography coupled with post-column derivatization fluorometry. J Chromatogr 1985; 344:115-23.

34 Harsing LG, Nagashima H, Duncalf D, Sylvester E, Goldiner PL. Determination of histamine concentrations in plasma by liquid chromatography/electrochemistry. Clin Chem 1986; 32:1823-7.

35 Arakawa Y, Tachibana S. A direct and sensitive determination of histamine in acid-deproteinized biological samples by high-performance liquid chromatography. Anal Biochem 1986; 158:20-7.

36 Scheinman BD, Devalia JL, Wylie G, Davies RJ. Histamine and $\mathrm{N}^{t}$-methylhistamine in circulation during intravenous infusion of histamine in normal volunteers. Agents Actions 1988; 25:263-6.

37 Czerwonka R, Tsikas D, Brunner G. High-performance liquid chromatographic determination of plasma histamine after pre-column derivatization with o-phtaldialdehyde. Chromatographia $1988 ; 25: 219-22$.

38 Asskali F, Förster H. Standardisierung einer chromatogra- 
phischen methode zur spezifischen und empfindlichen Histaminbestimmung. Lab Med 1989; 13:194-5.

39 Mita H, Yasueda H, Shida T. Simultaneous determination of histamine and $\mathrm{N}^{\tau}$-methylhistamine in human plasma and urine by gas chromatography-mass spectrometry. J Chromatogr 1980; 221:1-7.

40 Keyzer JJ, Wolthers BG, Muskiet FAJ, Breukelman H, Kaufman HF, de Vries K. Measurement of plasma histamine by stable isotope dilution gas chromatography-mass spectrometry: methodology and normal values. Anal Biochem 1984; 139:474-81.

41 Payne NA, Zirrolli JA, Gerber JG. Analysis of histamine and $\mathrm{N}^{\mathrm{T}}$-methyl-histamine by gas chromatography-negative ion-chemical ionization mass-spectrometry. Anal Biochem 1989; 178:414-20.

42 McBride P, Bradley D, Kaliner M. Evaluation of a radioimmunoassay for histamine measurement in biological fluids. J Allergy Clin Immunol 1988; 82:638-46.

43 Sertüner-Workshops Einbeck; Histamin- und Histaminrezeptor-antagonisten. Doenicke A, Lorenz W, eds. Berlin: Springer Verlag, 1985.

44 Lorenz W, Doenicke A. $\mathrm{H}_{1}$ and $\mathrm{H}_{2}$ blockade: a prophylactic principle in anaesthesia and surgery against histaminerelease responses of any degree of severity. Part I and part II. N Engl Reg Allergy Proc 1985; 6:37-57 and 174-94.

45 Keyzer JJ. Determinations of histamine and some of its metabolites and their clinical applications. Pharm Weelblad Sci Ed 1984; 6:218-20.

46 Lorenz W, Doenicke A, Schöning B, Neugebauer E. The role of histamine in adverse reactions to intravenous agents. In: Thornton A, ed. Adverse reactions of anaesthetic drugs. Amsterdam: Elsevier North Holland, 1981:169-238.

47 Beaven MA, Robinson-White A, Roderick NB, Kaufmann GL. The demonstration of histamine release in clinical conditions: a review of the past and present assay procedures. Klin Wochenschr 1982; 60:873-81.

48 Oosting E, Richardson FJ, Keyzer JJ, Wolthers BG, Agoston S, Langrehr D. Histamine metabolism after adverse reactions due to d-tubocurarine administration, Agents Actions 1987, 21:54-61.

49 Moss J, Rosow CE. Histamine release by narcotics and muscle relaxants in humans. Anaesthesiology 1983; 59:330-9.

50 Keyzer JJ, Breukelman H, Wolthers BG, Richardson FJ, de Monchy JGR. Measurement of N-methylhistamine concentrations in plasma and urine as a parameter for histamine release during anaphylactoid reactions. Agents Actions $1985 ; 16: 76-9$.

51 Neugebauer E, Lorenz W, Maroske D, Barthlen W, Ennis M. The role of mediators in septic/endotoxic shock; a metaanalysis evaluating the current status of histamine. Theor Surg 1987; 2:1-28.

52 Schwartz LB, Metcalfe DD, Miller JS, Earl H, Sullivan T. Tryptase levels as an indicator of mast-cell activation in systemic anaphylaxis and mastocytosis. N Engl J Med 1987; 316:1622-6.

53 Rosenbaum RL, Frieri M, Metcalfe DD. Patterns of skeletal scintigraphy and their relationship to plasma and urinary histamine levels in systemic mastocytosis. J Nucl Med 1984; 25:859-64.

54 McFadden ER, Soter NA, Ingram RH. Magnitude and site of airway response in asthmatics in relation to arterial histamine levels. J Allergy Clin Immunol 1980; 66:427-77.

55 Lorenz W, Thermann M, Messmer K, et al. Evaluation of histamine elimination curves in plasma and whole blood of several circulation regions: a method for studying kinetics of histamine release in the whole animal. Agents Actions 1974; 4:336-56.

56 Lorenz W, Barth H, Thermann M, Schmal A, Dormann P, Niemeyer I. Fluorometric histamine determination in canine plasma under normal conditions, following application of exogenous histamine, and during histamine release by haemacel. Hoppe-Seyler Z Physiol Chem 1974; 355:1097111.

57 Gleich GJ, Hull WM. Measurement of histamine: a quality control study. J Allergy Clin Immunol 1980; 66:295-8.

58 Buttner J, Borth R, Boutwell JH, Broughton PMG, Browyer RC. Approved recommendations (1983) on quality control in clinical chemistry part 5. external quality control. J Clin Chem Clin Biochem 1983; 21:885-92.

59 Lorenz W, Neugebauer E, Uvnäs B, et al. Munich consensus development conference on histamine determination. In: Uvnäs B, ed. Handbook of experimental pharmacology, Vol 18/3. Berlin: Springer-Verlag, 1990: in press.

60 Lorenz W, Uvnäs B. Histamine assays: chapter-writing by consensus. Lancet 1989, i: 1278.

61 Neugebauer E, Keyzer JJ, Oosting E, Lorenz W. Reliability of current techniques for histamine determination in human plasma: the european external quality control study 1988. Agents Actions 1990; 20: in press.

63 Morel AM, Delaage MA. Immunoanalysis of histamine through a novel chemical derivatization. J Allergy Clin Immunol 1988; 82:646-54.

64 Devalia JL, Scheimann BD, Davies RJ. Highly sensitive high-performance liquid chromatographic technique for the simultaneous measurement of histamine, 1-methylhistamine and other biogenic amines. J Chromatogr 1985; 343:407-12.

65 Lorenz W, Doenicke A, Neugebauer E, Schwartz B, Schmal A, Schöning B. Definition of histamine release in human subjects and experimental animals using plasma histamine determination in the whole individual. Agents Actions 1979; 9:35.

66 Oosting E, Keyzer JJ, Wolthers BG. Correlation between urinary levels of histamine metabolites in 24-hour urine and morning urine samples of man: influence of histamine-rich food. Agents Actions 1989; 27:205-7.

67 Lorenz W. Histamine release in man. Agents Actions 1975; 5:402-16.

68 Sheffer AL, Soter NA, McFadden ER, Austen KF. Exercise-induced anaphylaxis: a distinct form of physical allergy. J Allergy Clin Immunol 1983; 71:311-16.

69 Cho CH, Wu TC, Ting CW, Chen SW. Gastric and serum histamine in respiratory disorders and sepsis of newborns. IRCS Med Sci 1985; 13:200. 
This document is a scanned copy of a printed document. No warranty is given about the accuracy of the copy. Users should refer to the original published version of the material. 